\title{
O COMPORTAMENTO DOS GESTORES DO SETOR VAREJISTA DE ELETRODOMÉSTICOS: reagir ou adaptar-se?
}

\author{
Luana Ferrari KROMBAUER ${ }^{1}$ \\ Ariosto SPAREMBERGER ${ }^{2}$ \\ Luciano ZAMBERLAN ${ }^{3}$ \\ Gabriela CAPPELLARI ${ }^{4}$ \\ Jorge Oneide SAUSEN $^{5}$
}

\author{
${ }^{1}$ Especialista - UNIJUÍ - luana_krombauer@hotmail.com \\ ${ }^{2}$ Doutor - UNIJUÍ - ariosto@unijui.edu.br \\ ${ }^{3}$ Doutorando - UNIJUÍ - lucianoz@ unijui.edu.br \\ ${ }^{4}$ Doutoranda - UNIJUÍ - gabriela.cplr@gmail.com \\ ${ }^{5}$ Doutor - UNIJUÍ - josausen@unijui.edu.br
}

Recebido em: 29/12/2016 - Aprovado em: 05/05/2017 - Disponibilizado em: 01/07/2017

\begin{abstract}
RESUMO
O varejo é um setor que requer diariamente ações que visam à inovação. No entanto, a ação do gestor, principalmente em momentos de instabilidade econômica, requer muito controle e cautela nos negócios, pois ele é o elo entre o operacional e a alta cúpula de uma empresa. É necessário que o gestor desenvolva capacidade analítica e crítica frente a este cenário. Nesta direção, este artigo tem por objetivo identificar o comportamento dos gestores do setor varejista de eletrodomésticos frente às novas tecnologias e quais as ações dos mesmos, diante do impacto provocado na gestão da loja, considerando os fatores internos e externos. Para atender o objetivo, foi desenvolvida uma pesquisa exploratória e descritiva. Foram realizadas entrevistas previamente agendadas com cinco gestores de lojas do varejo, que trabalham no ramo de eletrodomésticos. Os resultados mostram que o e-commerce tem apresentado um crescimento significativo no mercado e tem se tornado uma forte tendência. Todavia, os gestores entrevistados demonstram que não se sentem ameaçados e acreditam que a cultura local não está voltada para este tipo de compra. Percebe-se que os gestores estão voltados para ações de reações ao cenário, aproximando-se do cliente por meio de estratégias voltadas a fidelização deste. As estratégias de retenção de clientes e novas prospecções são semelhantes em todas as empresas entrevistadas. Neste estudo, pode-se concluir que é imprescindível que as empresas estendam seus negócios à internet, uma vez que não se pode ignorar o número de e-consumidores, que vêm crescendo a cada dia.
\end{abstract}

Palavras-Chave: Gestor. Varejo. Eletrodomésticos. Novas tecnologias.

\begin{abstract}
Retail is a sector that requires daily actions aimed at innovation. However, the action of the manager, especially in times of economic instability, requires a lot of control and caution in business, since it is the link between the operational and the high summit of a company. It is necessary for the manager to develop analytical and critical capacity against this scenario. In this direction, this article aims to identify the behavior of the managers of the retail sector of home appliances in front of the new technologies and what their actions, given the impact caused in the management of the store, considering the internal and external factors. To meet the objective, an exploratory and descriptive research was developed. Previously scheduled interviews were conducted with five managers of retail stores, who work in the branch of household appliances. The results show that e-commerce has shown significant growth in the market and has become a strong trend. However, the managers interviewed demonstrate that they do not feel threatened and believe that the local culture is not geared towards this type of purchase. It is noticed that the managers are focused on actions of reactions to the scenario, approaching the client through strategies aimed at customer loyalty. Customer retention strategies and new surveys are similar across all companies interviewed. In this study, one can conclude that it is imperative that companies extend their business to the Internet, since one cannot ignore the number of e-consumers, which are growing every day.
\end{abstract}

Keywords: Manager. Retail. Home appliances. New technologies. 


\section{INTRODUÇÃO}

Diante da situação econômica, também no setor varejista, a única certeza é que a mudança e o acirramento da concorrência são contínuas e cada vez mais aceleradas no atual ambiente de negócio. Dessa forma, as empresas são desafiadas a enfrentar uma concorrência cada vez mais acirrada e a atender clientes com níveis de exigência

crescentes. Essas empresas necessitam de recursos inovadores para questões fundamentais como: a qualidade dos produtos e serviços, agilidade e flexibilidade no atendimento aos clientes e custos competitivos.

O setor varejista tem procurado encontrar mecanismos para superar barreiras e solucionar problemas com respostas criativas. Como característica, o varejo possui a vantagem de estar permanentemente próximo ao consumidor o que possibilita mais agilidade na detecção de tendências e na percepção de toda e qualquer mudança no perfil do consumidor, razão pela qual pode promover mudanças quase que simultâneas para atender às necessidades dos clientes. $\mathrm{Na}$ visão de Doni e Sillas (2007), a principal função do varejo é a prestação de serviço ao consumidor, pois leva produtos e serviços ao alcance dele e adiciona-lhes valor.

Os gestores têm um papel importantíssimo neste quadro, seja em pequenas, médias ou em grandes empresas. O papel do gestor é assegurar o desenvolvimento da empresa, por meio da geração sustentada de lucros. Para atingir este alvo primordial, precisa desempenhar autoridade que lhe foi conferida, dirigindo, coordenando e controlando os membros da sua equipe.

Mintzberg (2010) afirma que gerentes não conseguem um controle total de suas atividades, pois grande parte dos problemas com os quais ele lida são inesperados e, em algumas situações, são intratáveis. Além disso, o trabalho gerencial não é estritamente ligado ao relacionamento com subordinados, mas frequentemente se dá de forma lateral, em relações com colegas, sócios e clientes; e, ainda, a tecnologia.

O perfil do gerente de vendas de hoje é visto como sendo um profissional voltado para as pessoas, com habilidade no relacionamento interpessoal e comprometido com o aprimoramento de cada um da equipe. De um ponto de vista único os gerentes de loja tem um papel importante na formulação e na execução da estratégia no varejo. Devido ao contato diário com o cliente, os gerentes têm melhor conhecimento das necessidades dos clientes e das atividades da concorrência (LUCENA; MORGAD， 2007; LEVY; WEITX, 2000).

No ponto de vista de Stanton e Spiro (2000), o gerente de vendas exigente, controlador, interessado no volume de vendas está desaparecendo. Atualmente, os gerentes de vendas de sucesso são vistos como líderes 
de equipes, e não como chefes. Eles ainda dirigem e orientam pessoas, mas fazem isso por meio da colaboração e da delegação dos poderes em lugar do controle e do comando. Para ter sucesso no século XXI, os gerentes de vendas precisarão adaptar suas estratégias, seus estilos e atitudes.

Diante deste cenário, este estudo tem por objetivo identificar o comportamento dos gestores do setor varejista de eletrodomésticos diante do avanço doe-commerce e quais as principais ações dos gestores diante do impacto dos elementos internos e externos na gestão da loja.

O artigo está estruturado em quatro partes. Na primeira a introdução que aborda o tema e os objetivos do trabalho. Na segunda as bases teóricas, com ênfase em marketing, gestão, conceitos de prestação de serviço, ecommerce e atendimento. Em terceiro, os procedimentos metodológicos que apresentam a forma como o estudo foi realizado, o processo de coleta e análise dos dados. No quarto é abordada a apresentação e discussão dos resultados. Para finalização do presente estudo é apresentada as considerações finais e na sequência as referências bibliográficas.

\section{REFERENCIAL TEÓRICO}

\subsection{Marketing}

Muitas empresas crescem de maneira orgânica e demoram meses e até anos para começar a fazer marketing. O conceito de apenas vender algo é totalmente equivocado, pois o marketing se aprofunda em tudo que envolve o processo, bem como a produção, logística, comercialização e pós venda do produto/serviço.

Para Kotler (2003), marketing é a função empresarial que identifica necessidades e desejos insatisfeitos, define e mede sua magnitude e seu potencial de rentabilidade, especifica que mercados-alvo serão mais bem atendidos pela empresa, decide sobre produtos, serviços e programas adequados para servir a esses mercados selecionados e convoca a todos na organização para pensar no cliente e atender ao cliente.

Cobra (2005) acrescenta que o marketing funciona como uma ação de planejamento que leva a execução. Todas essas respostas são obtidas após saber: que mercado trabalhar, o tipo de produto que deve ser vendido, como divulgar e distribuir este produto, para finalmente executar a venda.

O marketing é uma atividade humana dirigida para satisfazer necessidades e desejos por meio de troca. Ao identificar desejos ou necessidades, busca-se satisfazê-los, comprando produtos ou serviços de quem tem a vender, estabelecendo assim uma troca no qual as organizações e clientes participam (KOTLER, 2010).

O marteking é essenciale não pode ser considerado como uma função separada. Ele deve ser visto como um todo ao considerar os objetivos da empresa e a opinião do cliente. 
Isto irá determinar o sucesso do produto ou serviço oferecido (DRUCKER, 2001). Esse processo não abrange apenas vender determinado produto existente, ele é essencial para fazer com que o consumidor torne a realizar a compra no mesmo local, assim como fortalecer a relação entre empresa e cliente. O lucro é apenas a consequência, mas não é o principal objetivo.

Etzel (2001) deu ênfase a esta visão do marketing definindo-o como um sistema de atividades que tem como objetivo planejar, estabelecer preços, promover e distribuir produtos que satisfaçam aos desejos e necessidades do público-alvo e atenda aos objetivos organizacionais.

Marketing é mais do que uma forma de sentir o mercado e adaptar produtos ou serviços, ele é um compromisso com a busca da melhoria da qualidade de vida das pessoas. Com essas exposições as empresas não podem mais confiar mas práticas antigas, pois a eficiencia já não é mais a mesma para atingir seu público alvo (COBRA, 1992).

\section{Morgado e Gonçalves (2001) dão} destaque à importância do marketing mix para as empresas. Conhecido por "composto de marketing" criado por Jerome McCarthy (1976) está relacionado aos “ $4 \mathrm{P}^{\prime} \mathrm{s}$ ” de marketing, ou seja, com o conjunto de variáveis controláveis que a empresa pode utilizar para influenciar a resposta dos consumidores. São eles: produto (product), preço (price), ponto (place), e promoção (promotion).

A função do marketing é então identificar as necessidades não satisfeitas, de modo a colocar no mercado produtos ou serviços que ao mesmo tempo, proporcionem satisfação dos consumidores, gerem resultados auspiciosos e valham a melhorar a condição de vida das pessoas e da comunidade em geral.

\subsection{Marketing de Varejo}

Etzel, Walker e Stanton (2001) enfatizam que os canais de distribuição são caracterizados por um conjunto de pessoas e empresas com a finalidade de levar o produto ao consumidor final. O setor varejista é um canal de distribuição que representa um elo entre produtores (fornecedores) e consumidores e torna mais eficiente a troca entre ambos.

$$
\text { É de Kotler (2000) a primeira }
$$
definição para se entender o que é varejo. $\mathrm{O}$ mesmo pode ser entendido como qualquer organização que venda para consumidores finais - seja um fabricante, atacadista ou um varejista - está fazendo varejo. A maneira como os produtos são vendidos (pessoalmente, por correio, telefone, por máquinas de venda ou pela internet) ou onde eles são vendidos (em uma loja, na rua, na casa do consumidor) não é importante.

Richter (1954) apud Las Casas (1994) também refere o varejo como sendo avenda 
em quantidades menores ao consumidor final e menciona que o varejo seja o processo de compra de produtos em quantidade relativamente grande dos produtores atacadistas e outros fornecedores e posterior venda em quantidades menores ao consumidor final. $\mathrm{O}$ varejo desempenha um papel muito importante no marketing, pois muitas decisões estratégicas de produtos, formas de comunicação, preço, promoções, marcas, embalagem e demais sofrem mudanças e alterações no fabricante e fornecedor.

Com relação às características do varejo, Cobra (1997) sintetizou quatro características importantes: (a) no varejo, quem inicia a compra geralmente é o consumidor, ao contrário da venda de fabricantes ou atacadistas para varejistas, a iniciativa é do vendedor dos primeiros; (b) o varejo tem um sentido de urgência. As pessoas desejam comprar e usar as mercadorias imediatamente; (c) a venda é efetuada geralmente em pequenas quantidades; (d) o varejo tem normalmente uma localização fixa e, por isso, precisa atrair compradores, uma vez que não pode ir aos compradores, como o fazem os vendedores de fabricantes, de atacadistas e de distribuidores.

Logo, o marketing de varejo tem como característica a comunicação com o consumidor sem focar especificamente em marca ou produto, mas em estratégias de promoções de venda e criação de um relacionamento cordial entre empresas e consumidores. Ou seja, o foco está em atuar na construção de uma parceria sólida com os consumidores, por meio das estratégias de comunicação para conquistar, se relacionar e fidelizar.

O primeiro passo para a aplicação do marketing no varejo, é a identificação dos desejos e das necessidades o mercado alvo. O varejista precisa concentrar a atenção na descoberta do que o consumidor deseja e necessita, pois, satisfazendo essas necessidades ele poderá realizar seus objetivos de lucros (COBRA, 1992).

De acordo com Parente (2000) o composto varejista corresponde à análise das variáveiscontroláveis e incontroláveis do ambiente de marketing. Estas variáveis são utilizadas como ferramentas de marketing por empresários para elaboração de estratégias no ramo varejista. As variáveis controláveis são aquelas que podem ser gerenciadas, redefinidas ou modificadasde acordo com as necessidades do empresário e do mercado. Para relacionar estas variáveis, adotam-se os 6Ps conforme Barry J. Mason (1994) apud Parente (2000) explorado no Quadro 1. 
Quadro 1 - Os 6Ps do Composto Varejista relacionado as suas decisões

\begin{tabular}{|c|c|}
\hline Vraine do Canpoto Vargita & Exraples de Desabes \\
\hline P- wir de Probete & Vanebade de Lanla Quabdak, Servio \\
\hline P-Prese & Precos, Credase, Beacliow Costor. \\
\hline P-Promadio & Aropezanda Ofeta Sisaleracio \\
\hline $\mathrm{P}$-apresatiag & Log Dequabaneatos, Plangerama \\
\hline P-Penal & 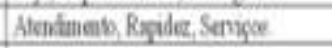 \\
\hline P- Fato & 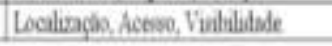 \\
\hline
\end{tabular}

Fonte: Parente (2000, p. 61).

Decidir o que vai compor o mix de produtos consiste em uma das decisões mais importantes de uma empresa varejista (PARENTE, 2000). Estes "6 P's" constituemse nas variáveis mais importantes que um varejista deve pensar para diferenciar e bem posicionar o seu negócio no mercado.

O assim chamado Marketing de Varejojá possui uma enorme gama de conhecimentos a serem aplicados na realidade das grandes corporações varejistas. Ainda para Levy (2000) os varejistas comunicam-se com os clientes por meio de cinco veículos: (a) anúncios; (b) promoções de vendas; (c) publicidade; (d) atmosfera da loja, merchandising e; (e) venda pessoal.

De acordo com Cobra (1997), as decisões estratégicas de produto, comunicação e preço dependem, em última instância, do varejo. A mudança de estratégia do varejo alterará ou afetará o composto de marketing de atacadistas e fabricantes. Para o autor, os varejistas devem concentrar a atenção nas necessidades e desejos do público-alvo. Sendo assim, os varejistas dispõem de algumas ferramentas de marketing descritas na Figura de número 1.
Figura 1: Ferramentas de marketing

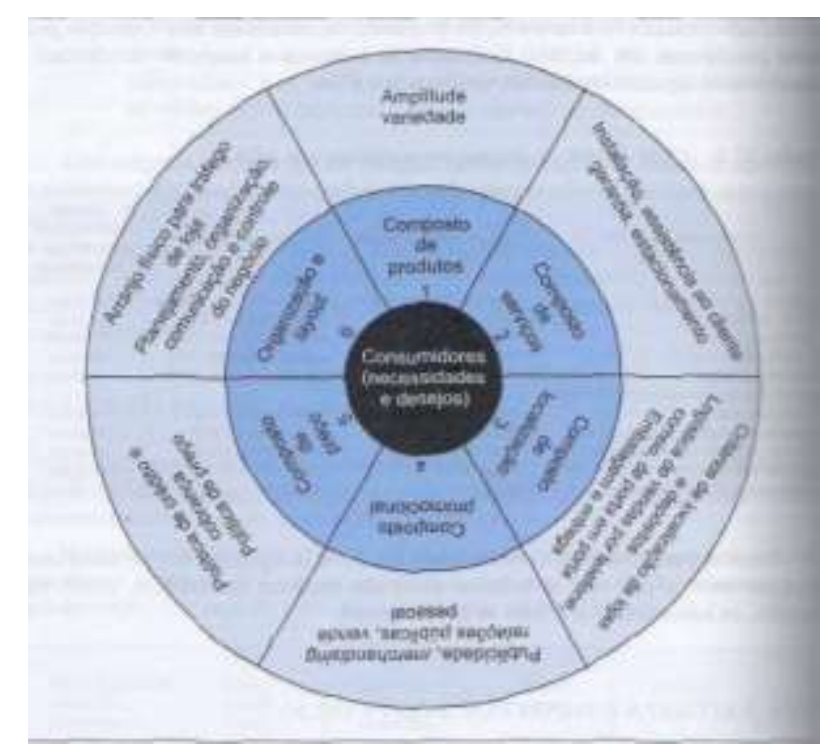

Fonte: Cobra (1997).

\subsection{Prestação de serviços}

Os serviços são atividades de natureza intangível que ocorrem em virtude da interação entre clientes e empregados. São performances ou atividades que a empresa realiza para satisfazer o mercado consumidor (GRÖNROOS, 1995). Desta forma, os serviços fazem parte do marketing como uma maneira de agregar valor ao produto. Serviço ao consumidor é o conjunto de atividades varejistas que aumentam o valor que os consumidores recebem quando fazem compras e adquirem mercadorias. Refere-se aos serviços de marketing, que acompanham a venda de bens tangíveis e intangíveis, agregando valor à sua oferta (COBRA, 1997).

Ultimamente, os serviços têm sido utilizados como estratégia pelas organizações que neles vêem neste uma maneira de criar um diferencial para a empresa (LEVY; WEITZ, 2000). A ideia de um papel 
estratégico para os serviços foi abordada por Cobra e Rangel (1992), quando definiram os serviços como forma de proporcionar tantas satisfações quantas forem possíveis pela posse do bem ou do serviço adquirido.

Nas empresas varejistas, existem diversos níveis de serviços que podem ser escolhidos pelo varejista de acordo com o seu negócio. Dentre a classificação, quatro alternativas foram sugeridas por Kotler (1998): (a) auto-serviço: neste conceito, o consumidor realiza suas próprias compras de acordo com informações dentro da loja, por meio da sinalização, cartazes e rótulos de produtos; (b) auto-seleção: neste tipo de serviço, o consumidor também realiza suas compras, com base em informações dentro da loja. No entanto, se necessário pode solicitar a ajuda de algum vendedor disponível no local; (c) serviços limitados: são realizados em lojas em que o consumidor necessita de mais informações sobre o produto que deseja comprar. Geralmente envolve funcionários bem treinados e serviços extras como de entrega em domicílio; (d) serviço completo: quem adota este tipo de serviço são empresas com ênfase em serviços e que disponibilizam pessoal de vendas em todas as fases do processo de compra. Oferecem boas instalações, locais de espera confortáveis e serviços diferenciados.

Já segundo Dunne e Lusch (1999), os serviços oferecidos no varejo podem ser classificados segundo três categorias: antes, durante e após a transação. Antes da transação, os clientes levam em consideração informações sobre os produtos e a busca de alternativas para um melhor negócio. A fase “durante a transação" ajuda o estágio de decisão de compra e corresponde aos processos existentes para que a transação seja completada. Na última fase é verificada a reação pós-compra e a satisfação do consumidor com os serviços.

Há uma variedade de serviços de marketing para valorizar e distinguir uma marca desde a especificação do produto com os formadores de opinião até serviços de entrega, garantia, manutenção e do atendimento de reclamações dos clientes, especificando que não há limites, pois dependem da imaginação e criatividade do profissional de marketing para surpreender as expectativas dos clientes. Os serviços no varejo desempenham uma função estratégica na busca de um diferencial e competitividade no mercado (COBRA (2009).

\subsection{Atendimento}

Atualmente, o papel do profissional que trabalha no varejo é mais abrangente do que em qualquer outra época da historia da atividade. Neste novo mercado só consegue sobreviver o profissional de vendas que seja reconhecido pelos seus clientes como alguém que se preocupa com eles e busca atender suas necessidades (preço e um bom atendimento). 
Para Levy e Weitz (2000), o atendimento ao cliente é o conjunto de atividades e programas assumidos pelos varejistas para tornar a experiência de compra mais recompensadora para seus clientes. Ainda ele acrescenta que essas atividades aumentam o valor que os clientes recebem a partir das mercadorias e serviços que compram.

Todo atendimento desdobra-se em uma lista de atributos: velocidade, cordialidade, conhecimento, solução de problemas e assim por diante. Cada pessoa atribui diferentes pesos a estes atributos de atendimento em diferentes momentos e contextos. Dizer que oferece um bom atendimento não é o bastante (KOTLER, 2000).

É exatamente a característica de um produto tangível ou intangível, adquirido, que vai garantir a satisfação do cliente e, também, o sucesso da empresa. E a qualidade dos serviços oferecidos por uma empresa consiste nos detalhes da relação do atendimento ao cliente. Segundo Lacerda (2005), qualidade é a filosofia de gestão que procura alcançar o pleno atendimento das necessidades e a máxima satisfação das expectativas dos clientes.

Segundo Neves (2004), acredita-se que, na luta pela sobrevivência, as organizações têm buscado oferecer qualidade em produtos e serviços. Mas, diante da concorrência, que oferece os mesmos produtos, o atendimento ao cliente é o principal fator de vantagem competitiva entre as organizações.

Com relação aos profissionais de venda, Las Casas (2004), não importa a situação econômica, épocas de crises ou de desenvolvimento, as empresas sempre precisarão de profissionais de vendas com maior ou menor intensidade. A profissão de vendas apresenta características positivas diversas, e uma delas é a de contribuir para o desenvolvimento de profissionais de alto nível. Desenvolver a capacidade de vender significa ampliar a própria habilidade para lidar com qualquer situação e, consequentemente, aumentar as oportunidades de obter melhores resultados.

Ainda para Neves (2006), o processo de vendas é uma sequência de passos ou etapas por meio dos quais os vendedores realizam a venda. Sendo a pré-venda, venda e pós-venda, importantes etapas para o sucesso do processo.

Não há mais espaço para o vendedor sem conhecimento, sem treinamento, sem argumentos. O que um consumidor quer de um vendedor é prestação de serviços, um bom atendimento, um vendedor preparado. E o que é necessário para o vendedor prestar um bom serviço é ter conhecimento técnico de vendas, tirar as dúvidas dos clientes, vender exatamente a necessidade do cliente, nem aquém nem acima de sua capacidade de absorção (MACEDO, 2001). 
O mercado disputado, transbordando de ofertas e o público com disponibilidade de escolha em diversos níveis, afinal hoje a internet está abrindo as fronteiras e diminuindo as distâncias deixando o consumidor muito à vontade para decidir qual é a melhor alternativa mercadológica, e o mercado virtual vem ganhando seu espaço a cada dia, pois hoje o consumidor não procura somente o preço e sim um atendimento, diferenciado e personalizado.

\subsection{O papel do gestor no varejo}

Atualmente é explícito o valor do varejo na dinâmica do mercado e na economia. Diversas empresas comercializam produtos e serviços diretamente ao consumidor, gerando um volume de milhões de reais em transações.

O gerente é, dentro de uma loja de varejo, a pessoa responsável por fazer com que a loja obtenha sucesso, é responsável pela contratação, treinamento e montagem da equipe de vendas, é a pessoa que conseguirá tirar o máximo de rendimento de sua equipe de vendedores, dando orientações, corrigindo procedimentos, incentivando e motivando os vendedores, enfim, exercendo o papel de um líder de vendas.

Lucena e Morgado (2007) descrevem o perfil do gerente de vendas de hoje como sendo um profissional voltado para as pessoas, com habilidade no relacionamento interpessoal e comprometido com o aprimoramento de cada um da equipe.

Ainda para Levy e Weitz (2000), de um ponto de vista único os gerentes de loja tem um papel importante na formulação e na execução da estratégia no varejo. Ainda, os mesmos apontam que devido ao contato diário com o cliente eles têm melhor conhecimento das necessidades dos clientes e das atividades da concorrência.

O gerente necessita compreender cada indivíduo e seu papel dentro da equipe estilo de trabalho, estímulos, pontos fortes e limitações, e gerenciar cada um, de modo a transformá-los no vendedor que o mercado precisa. Para melhor desempenhar estes papéis os gerentes de vendas assumem responsabilidades e enfrentam grandes desafios no uso de ferramentas que objetivam um melhor funcionamento e maior rendimento para sua empresa. As ferramentas mais utilizadas pelos gerentes são treinamento, estatísticas de vendas, metas de vendas, gerenciamento da equipe de vendas.

Contudo, Mintzberg (2010) procurou discutir a natureza do trabalho dos gestores tendo como foco a pergunta: $O$ que os administradores fazem? E define que coordenar, organizar, planejar e controlar, dizem muito pouco sobre o trabalho dos gerentes em seu cotidiano. Ainda o autor descreve as tarefas do executivo distribuindoos em: interpessoal, informacional e decisional. De forma sucinta, tem-se que o 
papel interpessoal refere-se à manutenção da imagem do chefe por meio da participação em eventos, do exercício da liderança e do contato; o informacional compreende o monitoramento e a disseminação da informação tanto dentro quanto fora da empresa; e o decisional diz respeito à atuação empreendedora que o executivo deve adotar para melhorar constantemente sua unidade de trabalho, manipular os distúrbios, responsabilizar-se diretamente pela adaptação a pressões, alocar recursos e negociar.

No ponto de vista de Stanton e Spirro (2000) o gerente de vendas exigente, controlador, interessado no volume de vendas está desaparecendo. Atualmente, os gerentes de vendas de sucesso são vistos como líderes de equipes, e não como chefes. Eles ainda dirigem e orientam pessoas, mas fazem isso por meio da colaboração e da delegação dos poderes em lugar do controle e do comando. Para ter sucesso no século XXI, os gerentes de vendas precisarão adaptar suas estratégias, seus estilos e atitudes.

As responsabilidades dos gerentes podem ser divididas em quatro categorias principais: (a) gerenciamento de empregados; (b) controle de custos; (c) gerenciamento de mercadorias e; (d) atendimento ao cliente. Os mesmos ainda acrescentam que uma das principais e importantes funções dos gerentes é aumentar a produtividade dos empregados, recrutando pessoas eficientes e que podem assumir mais responsabilidades a serem promovidos para cargos de nível gerencial (LEVY; WEITZ, 2000).

\subsection{E- commerce}

Segundo Albertin (2001), e-commerce é o processo de negócios realizados via rede mundial de computadores, ou seja, por meio da internet, utilizando as tecnologias existentes que possibilitem essa ação, e atendendo assim aos objetivos do negócio em questão. Esse processo permite a compra e venda de bens (tangíveis e intangíveis) disponíveis em lojas ou prestadoras de serviços que utilizam o meio virtual para vender ou comprar produtos ou serviços.

Já Kalakota e Whinston (1997) apud Nakagaw (2008), dependendo da abordagem em questão o e-commerce pode ter diferente significados: (a) com relação a comunicações, e-commerce é a transmissão de informações,produtos/serviços, ou transações financeiras que venha a utilizar a linha telefônica, a rede mundial de computadores, ou qualquer outro meio digital ou eletrônico; (b) com relação ao processo que envolve negócios, o e-commerce é a utilização de determinada tecnologia que facilite ou gere automatização de transações financeiras e de negócios, bem como o fluxo constante de dados; (c) relativo ao serviço, o e-commerce possibilita uma relação direta entre a possibilidade das empresas, oferecer seus produtos e serviços a clientes que querem cortar custos seja de deslocamento até uma 
loja física, ou a empresa que não precisa dispor de todo um grupo de colaboradores em lojas físicas; (e) levando para a característica on-line, o e-commerce permite a compra $\mathrm{e}$ venda de produtos ou serviços via internet, podendo ser realizada por meio de smartphones, tablets, computadores de mesa ou notebooks. No entanto, existem diversos tipos de transações compra e venda, sendo as mais importantes:

\section{-B2C (Business-to-consumer),}

negócios que tem inicio em uma organização para clientes finais, sendo esse o principal modelo de negócio online, sendo esse definido como varejo-online. Servindo de exemplos temos: passarela.com.br, ebay.com, centauro.com.br, casasbahia.com.br, entre outras mais.

-B2B (Business-to-business), estes são negócios que seguem uma rotina de empresa para empresa, sendo esse o modelo mais comum quando se trata de troca de informações por empresas, por meio de emails, realização de orçamentos, entre outros.

-C2C (Consumer-to-consumer), este exemplo de e-commerce é um dos mais populares entre pessoas físicas que buscam vender itens comprados que não satisfizeram seus anseios, ou que já não possuem mais utilidade para as mesmas, tendo como exemplo o site de compras mercadolivre.com.br.

De acordo com Korgaonkar e Wolin (1999) apud Morgado (2003), existem diversos tipos de motivações e ou atitudes que podem favorecer a utilização da internet para compras on-line, sendo esses os principais: (a) a fuga da realidade por meio de atividades que por sejam prazerosas ao individuo, por meio da internet, levando esse a visitar sites e lojas virtuais; (b) satisfação da necessidade por conhecimento de maneira mais veloz e menos onerosa; (c) o controle total do tempo, análise e pesquisa mais criteriosa dos produtos e serviços desejados; (d) a socialização e troca de informação sobre determinado produto ou serviço em sites de reclamações ou informações; (e) a maior comparação de preços de produtos e serviços, visto que não existe a pressão de um terceiro para a compra do produto visualizado pelo cliente.

\section{METODOLOGIA}

De acordo com Vergara (2004), quanto aos fins esta pesquisa é classificada como exploratória e descritiva. A etapa exploratória foi realizada por meio da pesquisa bibliográfica em livros e estudos relacionados ao tema. Gil (2002) explica que as pesquisas exploratórias têm como objetivo proporcionar maior familiaridade com o problema, com vistas a torná-lo mais explícito.

A pesquisa é descritiva, pois tem por objetivo conhecer as características dos gestores que trabalham no segmento varejista tradicional, por meio da aplicação de questionários focados no assunto. 
Para Malhotra (2001), a pesquisa descritiva pode ser efetuada, por meio de dois métodos: levantamento e observação. $\mathrm{O}$ Método de levantamento se caracteriza pelo interrogatório dos participantes por meio de perguntas que forneçam informações sobre seu comportamento, intenções, atitudes, percepções, motivações e características demográficas e de estilo de vida. O método levantamento possibilitou a busca de informações acerca da percepção dos gestores do setor varejista de eletrodomésticos diante da nova formatação e desenho do setor varejista provocado principalmente pela tecnologia que fez surgir o $e$-commercee quais as principais ações dos gestores diante do impacto dos elementos internos e externos na gestão da loja.

Quanto à abordagem de pesquisa pode ser classificada como qualitativa. Para Godoy (1995) a pesquisa qualitativa envolve a obtenção de dados descritivos sobre pessoas, lugares e processos interativos pelo contato direto do pesquisador com a situação estudada, procurando compreender os fenômenos segundo a perspectiva dos sujeitos, ou seja, dos participantes da situação em estudo. A entrevista em profundidade é uma técnica para se obter dados qualitativos. É uma entrevista não estruturada, direta, pessoal, em que um único respondente é entrevistado de cada vez por um entrevistador treinado, para descobrir motivações, crenças, atitudes e sensações com relação a algum assunto (ZAMBERLAN ET AL, 2014).

Para a coleta de dados, utilizou-se um instrumento em forma de questionário, com perguntas abertas, aplicado aos gestores do varejo por meio de contato direto em forma de entrevista. Isto permitiu a compreensão mais detalhada do contexto por meio da concepção das características situacionais apresentadas pelos entrevistados, à medida que permitiu ao pesquisador contato direto com o fenômeno em estudo (RICHARDSON, 1999).

O período das entrevistas ocorreu de setembro a dezembro de 2015. As conversações foram previamente agendadas e tiveram duração aproximada de 30 a 40 minutos. As empresas implicadas no estudo são todas redes de lojas, três das empresas possuíam mais filiais e abrangem a região sul.

A amostra dos sujeitos da pesquisa é caracterizada pelo tipo não probabilística, uma vez que os entrevistados foram escolhidos pelo critério acessibilidade e conveniência, tendo em vista os objetivos da pesquisa. Neste sentido, a amostra deste estudo é composta por cinco gerentes. Para interpretar e entender os dados coletados, o estudo utilizou a técnica da análise de discurso. Segundo Fernandes (2008), a análise de discurso é a análise da fala em contexto. Ela ajuda a compreender como as pessoas pensam e agem no mundo concreto.

$\mathrm{Na}$ análise de discurso foi realizada a transcrição dos resultados conforme a opinião 
e ponto de vista dos gestores entrevistados. Os dados foram tratados de forma qualitativa. Esta forma, segundo Vergara (2004), caracteriza-se por ser uma análise do tipo descritiva, observando o conteúdo das respostas obtidas.

\section{RESULTADOS E DISCUSSÃO}

Foram realizadas entrevistas com cinco gerentes do sexo masculino. Com relação à idade, estão na faixa etária de trinta a quarenta anos. Quanto ao tempo de experiência na função dois gerentes têm menos de cinco anos de experiência, dois dos entrevistados têm entre seis anos como gerentes e um tem mais de dez anos comandando lojas de varejo. Para preservar o anonimato dos entrevistados e de suas organizações todos os gerentes são identificados por um número sendo Gerente 1 , Gerente 2, Gerente 3, Gerente 4 e Gerente 5.

\subsection{Desafios diante do e-commerce}

Quanto aos resultados da pesquisa, foram identificados alguns pontos em comum com relação aos desafios diante do $e$ commerce.Percebe-se basicamente que os gerentes de vendas possuem duas grandes responsabilidades, ou podem ser chamados de desafios, de acordo com o seu grau de percepção. Primeiramente é compensar por meio do bom atendimento e outros benefícios as diferenças de preço de loja dos eletrodomésticos para com os preços oferecidos por meio de compras on-line e $e$ commerce.

Em segundo lugar, há uma grande preocupação com a equipe de vendas, desde a contratação, passando pela ambientação, treinamento e desempenho do funcionário na loja, e chegando à motivação do vendedor. Os gerentes possuem um papel de liderança fundamental no processo de aprimorando de vendedores, objetivando atingir as metas de vendas, então daí surge à necessidade da preocupação com a equipe de vendas.

Em alguns momentos, as lojas do varejo tradicional, acabam se tornando apenas escoadoras da produção e seus gestores não possuem autoridade para escolher a grade de produtos que mais agrade a seu público-alvo ou na definição de uma política de preços que esteja de acordo com o posicionamento estratégico. A falta de autonomia para tomar decisões tem sido uma das principais causas de fracasso nos movimentos de integração à frente.

Com base nesta perspectiva os gestores foram questionados quanto à representação dos eletrodomésticos nas vendas e-commerce. Todos os gerentes apontaram os eletrodomésticos como responsáveis por cerca de $30 \%$ a $40 \%$ do faturamento das lojas. Para o Gerente 1, a tendência é deixar a loja cada vez mais próxima do e-commerce, onde ao acessar o site da loja por meio de um localizador o cliente pode procurar a loja mais próxima. 
Existem projetos sendo desenvolvidos onde o cliente poderá procurar o produto na loja mais próxima e consultar seu estoque, se tem o produto disponível para entrega.

Na mesma acepção o Gerente 2 relata que o e-commerce não afeta muito as vendas da loja, pois em seu ponto de vista o público procura mais o relacionamento entre loja e vendedor. O Gerente 5 também apresentou essa percepção e acrescenta que o $e$ commerce é um mercado em expansão, mas que é muito perceptível a insegurança por parte do consumidor por esse meio de compra. O gestor frisa que o relacionamento e o contato com o cliente é essencial para ofertar o produto correto. Esta visão é defendida por Levy \&Weitz (2000), que destaca a competência do gerente de loja por meio da capacidade de conhecer seus clientes e adequar as ofertas dos produtos de acordo com as necessidades do comprador.

Ainda, o Gerente 3 expõe que o $e$ commerce tem afetado consideravelmente para o fechamento de algumas vendas. Para enfrentar esta situação, o gestor relata que tenta chegar ao valor mais próximo possível para fechar a venda. Aponta que as vendas on-line são constantemente uma luta injusta de certa forma, pois não possuem custos como pessoal, espaço físico e suporte, enfim demais outros custos que uma loja física possui, além de não arrecadar fundos para o município e não gerar empregos. Ressalta a necessidade de o consumidor adquirir os produtos na sua cidade de origem, onde os impostos arrecadados se revertem em investimento em âmbito social. Também comenta que muitos consumidores não tem mais buscado vinculo e relacionamento, visando apenas o produto.

No mesmo ponto de vista, o Gerente 4 afirma que o e-commerce afeta sim as vendas, porém de forma moderada. Ressalta que nossa região ainda possui uma cultura muito bairrista, onde os consumidores ainda gostam de ir até a loja, de tocar e ver o produto. Aponta que existe uma grande diferença de despesas das vendas on-line para uma loja, pois esta em seu espaço possui muitos custos e tributações que o e-commerce não tem. Ocorrem situações também aonde o cliente vem até a empresa e mesmo com uma diferença de 10 a $15 \%$ do site, ele acaba comprando na loja, pois está diante do produto e prefere levar o produto no momento em que a compra é efetivada.

O cliente com este comportamento não é afetado pelo serviço do $e$-commerce e não é sensível ao preço. Pois esta modalidade atende clientes que querem cortar custos de deslocamento até uma loja física (NAKAGAWA, 2008).

\subsection{Ações dos Gestores frente ao impacto dos elementos internos e externos}

Quando questionados ao processo da gestão, se é possível observar o impacto de fatores (internos e externos) nos resultados a 
empresa, o Gerente 1 aponta que a questão econômica ( recessão) é o que mais tem impactado, pois o setor depende do poder de compra do consumidor que com o mercado retraído acaba reduzindo suas aquisições. O aumento do desemprego tem impacto moderado nas vendas igualmente como a inadimplência, onde a empresa possui uma estrutura e um mecanismo para se antecipar e precaver aos riscos. Hoje há um crédito que está mais retraído, difícil. A inadimplência desta empresa está em menos de 5\%. Mesmo com todo cenário econômico desfavorável a empresa pode comemorar pois tem apresentado crescimento na área de consórcio, devido as menores taxas administrativas, sendo que muitos clientes optam por este produto. $\mathrm{O}$ gerente utilizou como exemplo o valor da carta de crédito onde o cliente usa a mesma de entrada para alguma aquisição de produto. Os consórcios cresceram mais de $30 \%$ para esta empresa nos últimos 5 anos.

Neste mesmo cenário o Gerente 2 expõe que havendo fatores externos negativos a relação entre os meios de comunicação como a mídia e a economia é preocupante para o setor. A mídia faz divulgação negativa que impacta no comportamento das pessoas, as quais deixam de consumir e as fábricas acabam diminuindo sua produção dando sequência em todo o restante da cadeia. Isto provoca demissões e aumenta a inadimplência. Relacionado às vendas, existe uma pequena queda. Partindo dessa visão, o
Gerente 3 aponta que com relação aos fatores externos o gestor tem procurado blindar e filtrar as informações, para não deixar a questão de o cenário econômico afetar ainda mais. Com relação à venda a empresa se manteve no mesmo patamar, porém os custos se elevaram um pouco.

Os gestores também foram questionados quanto à percepção em situações distintas da economia, como percebem e quais ações e medidas é executado no negócio em um período de instabilidade. Nesse aspecto o Gerente 4 coloca que a empresa passa agir mais pró ativa em cenário de instabilidade, como já estavam antenadas as previsões houve cuidados em todos os departamentos como de compras, para não haver acumulo de estoque, redução de despesas internas ( energia elétrica, material de consumo) e readequações de cargos e funções tanto em nível de loja, quanto em nível de rede e centros administrativos. O gestor afirma que em pequenos cuidados e questões simples resultam em uma economia de $10 \%$ a $15 \%$ em energia elétrica. Já em cenário de crescimento procuram manter o mesmo padrão de atendimento e políticas de preço.

Ações semelhantes de redução de despesas foram adotadas pelos Gerentes 1, $3 \mathrm{e}$ 4, mas todos afirmaram que evitam reduções no quadro pessoal em períodos de instabilidade, apenas procuram realizar ajustes para desligar os colaboradores que não estão ajustados com os objetivos da empresa. 
Ainda diante da mesma questão, o Gerente 5 afirma que são realizadas muitas ações de marketing diferenciadas de divulgação, com o objetivo de trazer o cliente até a loja. O gestor define o período( 2015) como um período positivo para mudanças e busca de alternativas, tais como ligações e visitas aos clientes e agendamentos para venda de móveis planejados.

\subsubsection{Gestão interna}

Os gestores foram questionados com relação à autonomia (descontos, prazo de pagamento, promoções e demais) delegação e capacidade de julgar, como considera este fator dentro de sua gestão e ainda como o processo decisório pode ser caracterizada. $\mathrm{O}$ Gerente 1 relata que em alguns campos o gestor possui total autonomia, na linha de frente, quanto a preços, descontos, possuem liberdade e poder de atuação, o que não ocorre da mesma forma com relação à frente administrativa na visão macro que tem que entrar em contato com outros supervisores. $\mathrm{O}$ gestor define o processo de gestão como simples, mesmo sendo necessário às vezes assumir decisões difíceis. O mesmo ocorre com o Gerente 2 afirma que:

\footnotetext{
“Com relação a preço e negociação o gestor possui autonomia ate determinado ponto, passando do que é lhe cabível entra em contato com a matriz que auxilia o processo de negociação, sendo este contato com a matriz muito rápido e ágil. $O$ gestor define a empresa como uma empresa humana e simples, preocupada com as pessoas (colaboradores e clientes) que visa seu foco maior na venda, atendimento da
}

necessidade do cliente. Não se exigem outros serviços agregados a compra do produto, que estes de faz perder o foco na venda".

De forma distinta o Gerente 3 aponta que seu nível de autonomia é estabelecido por meio dos resultados de sua gestão, quanto melhores os resultados apresentados, melhor seu nível de autonomia, podendo variar mensalmente. Isso resulta na busca pelo erro zero, onde a empresa estimula que o gestor administre o negócio como se fosse dele.

Ao mesmo tempo com relação à autonomia o Gerente 4 apresenta que possui até um determinado patamar de descontos e preços bem consideráveis. Incidindo disso é necessário entrar em contato com o departamento de compras por meio de um canal de comunicação interno, onde o feedback ocorre no mesmo instante. Com relação aos prazos de pagamento existem opções no próprio sistema. O gestor relata ter uma ligação eficiente com os outros departamentos da empresa, onde possuem abertura para opinar e auxiliar até na compra de produtos, como por exemplo, as linhas sazonais. O processo pode ser considerado ágil e eficiente.

Ainda neste aspecto o Gerente 5 afirma que possui um nível de autonomia superior ao dos vendedores. Ao exceder a sua autonomia vai para uma mesa de negociação com a matriz e que com esta possui várias vias de comunicação, incluindo um contato 
rápido e fácil e um departamento responsável para dar este suporte e orientação.

\subsubsection{Gestão de clientes}

Neste sentido os gestores foram indagados como trabalham com sua carteira de clientes, se realizam atividades de pós venda e quais estratégias utilizam para se diferenciar do varejo eletrônico. Em geral, os gestores frisaram que o mais importante acima de tudo é o bom atendimento e o relacionamento com o cliente, ofertando produtos certos e que atendam as necessidades dos mesmos. $\mathrm{O}$ varejista precisa concentrar a atenção na descoberta do que o consumidor deseja e necessita, pois, satisfazendo essas necessidades ele poderá realizar seus objetivos de lucros (COBRA, 1992).

Foi abordado que em todos os casos a gestão da empresa orienta a equipe realizarem um pós venda, de modo que entrando em contato com o cliente depois da compra terão um feedback positivo ou negativo, também o pós venda ocorre de forma aleatória. O Gerente 1 e o Gerente 3 contam com a linha de cartões de crédito, onde os clientes podem efetuar compras em outros estabelecimentos comerciais, mas ainda assim fortalecendo o vinculo com a empresa.

O Gerente 1 ainda apresenta que são enviadas malas diretas para os clientes que possuem cadastro, de acordo com seu perfil e produtos de seu interesse em períodos mensais. Também de três em três meses alguns clientes pré-definidos são convidados a ir até a loja para concorrer a prêmios. Logo como diferencial da concorrência o Gerente 2 coloca que possuem crediário próprio que não é regulado por nenhuma instituição financeira, aspecto esse que facilita e agiliza muito a abertura de crediário pois o cliente tem retorno imediato, já podendo efetuar a compra no mesmo instante.

O Gerente 3 assevera que a tecnologia tem auxiliado de forma positiva, pois por meio dela são disponibilizados aplicativos que possibilitam realizar diversas funções, desde cobrança, como vendas, e também conseguem gerar listagens de clientes ativos, inativos, e trabalhar com este público. Ainda acrescenta como principal estratégia de diferenciação e sendo pioneira em executar o projeto de ressarcimento ao cliente, onde quando o cliente não sendo atendido no prazo de entrega informado do produto, ele ganha o valor do bem como indenização e ainda recebe o seu produto adquirido, auferindo duas vezes e saindo totalmente satisfeito. Esse projeto visa resgatar a credibilidade da empresa perante o cliente, sendo uma corrente onde os fornecedores também são cobrados ao não cumprir seus prazos informados.

Como diferencial o Gerente 4 define que para agregar valor ao produto a equipe de vendas tem que ser ter conhecimento pleno e total do que se está oferecendo, baseado nisso a empresa tem contratado um técnico em 
informática que fica na loja para auxiliar nas vendas na linha de informática, sendo um dos departamentos que os clientes mais sentem dificuldades e os produtos estão cada vez mais inovadores. Agregar valor ao produto é uma estratégia que pode diferenciar a oferta, principalmente no varejo onde há comoditização de produtos e serviços. Desta forma, os serviços fazem parte do marketing como uma maneira de agregar valor ao produto (COBRA, 1997).

Uma das principais estratégias para garantir o sucesso da empresa é se destacar e trabalhar com foco na linha de móveis, coloca o Gerente 5.

\subsubsection{Estratégias de marketing}

O marketing tem ainda a função de atrair novos clientes e manter o rol de clientes sempre renovado. Neste sentido os Gerentes foram questionados quanto às quais ferramentas e estratégias de marketing as empresas têm adotado. As redes sociais, o telemarketing e as campanhas promocionais são as ferramentas mais eficientes utilizadas hoje pela empresa, afirma o Gerente 1. Também apresenta que o fato dos prêmios das campanhas promocionais serem expressivos tem impacto positivo com os clientes e auxilia no processo de fechamento de venda.

\section{O Gerente 2 argumenta que o} impactou nas vendas foi o novo ponto de localização e o layout interno, apresentando resultados positivos, de modo que a empresa tem atraído novos clientes. Também atenta para a grande importância da vitrine, onde enfatiza o fato de mantê-la preservada com novos produtos semanalmente. Utilizam como meios de comunicação como rádio, televisão, carro de som e ainda a distribuição de folders. O Gerente 3 sustenta que o marketing na empresa é centralizado na matriz, porém não se detém somente a isto, o departamento também trabalha aliado as lojas, não cuida somente de propaganda mas disponibiliza muitas listagens de clientes são enviadas, cria programas de aproximação com o cliente. Com relação aos folders de promoção são produzidos na matriz, sendo que é possível os gestores enviarem sugestões ou reclamações.

De maneira arrojada o Gerente 4 utiliza como marketing de relacionamento maior proximidade com a comunidade e aponta ótimos resultados a partir dessa forma de atuação. Ainda ressalta o mesmo que o fator atendimento é um grande e continua sendo o principal diferencial.O atendimento ao cliente é o conjunto de atividades e programas assumidos pelos varejistas para tornar a experiência de compra mais recompensadora para seus clientes. Ainda ele acrescenta que essas atividades aumentam o valor que os clientes recebem a partir das mercadorias e serviços que compram (LEVY; WEITZ, 2000).

$\mathrm{O}$ fato de algumas decisões de marketing ser enviadas da matriz é muito favorável, pois elimina o gerente destas 
decisões, tornando possível um foco maior na produtividade, acrescenta.

\section{CONSIDERAÇÕES FINAIS}

Percebe-se a partir do estudo que a venda via e-commerce tem obtido um crescimento nos últimos anos. O consumidor tem cada vez mais acesso a informação, facilidades de pagamento e busca melhor condições de negociação.

O Brasil é o quinto país que mais comercializa produtos on-line, estando atrás da China, Estados Unidos, Índia e Japão. No ano de 2014, o e-commerce girou mais de 35,8 bilhões de reais no Brasil e, no ano de 2015 esse número superou os 43 bilhões de reais (E-COMMERCE, 2015).

$\mathrm{O}$ Comércio eletrônico faturou $\mathrm{R} \$$ 18,6 bilhões no primeiro semestre de 2015, crescimento nominal de $16 \%$ na comparação com o mesmo período de 2014. Por faturamento, eletrodomésticos está no topo com 25\% de participação; seguida por telefonia/celulares com 18\%; eletrônicos, com $12 \%$, entre outros (E-BIT, 2016).

Pode-se afirmar que a partir dos resultados, que os gestores entrevistados não se sentem muito ameaçados pelo e-commerce, pois acreditam não ser uma forte tendência cultural da região. Contudo, criam estratégias que oferecem aos clientes vantagens $\mathrm{e}$ benefícios, contrapondo as condições encontradas pelo comprador na modalidade $e$ -
É evidente que a mudança chegou e que o e-commerce é um caminho sem volta $\mathrm{e}$ que o varejo tradicional precisa se reinventar permanentemente. No entanto, não são apenas as novas tecnologias que hoje permitem uma experiência mais completa e integrada nas lojas físicas, são questões ligadas ao comportamento do consumidor que já estão sendo estudadas e aplicadas tanto nas lojas como nos sites e-commerce. É preciso envolver o consumidor e convidá-lo a participar. A experiência não precisa ser grandiosa. Porém, precisa ser sempre inusitada, surpreendente.

Ainda pode-se perceber a deficiência da qualificação do quadro funcional resultante do investimento mínimo em cursos de qualificação e de motivação. Em algumas lojas é de responsabilidade do gestor, o qual já possui muitas outras atividades e funções a desempenhar. Treinamentos on-line e cursos podem ser aferidos seus resultados por meio de indicadores de desempenho.

É possível aludir que agora o equilíbrio entre poderes pendeu a favor do consumidor, visto que este exerce um nível de controle nunca antes visto. O varejo físico não tem alternativa a não ser entender a mentalidade dos consumidores e criar estratégias que possam trazer benefícios aos clientes, principalmente compensando preços competitivos que são oferecidos pelo modelo e-commerce.

commerce. 
Os brotados da pesquisa mostram que os gestores estão sendo desafiados a manter suas lojas competitivas diante de um cenário complexo e de acirrada concorrência. Além da disputa existente entre as lojas físicas, o comércio virtual é sem dúvida a invenção que está provocando ações proativas e imediatas por parte do varejo físico.

Os resultados da pesquisa reiteram a posição dos autores (MINTZBERG 2010; LUCENA; MORGAD, 2007; LEVY; WEITX, 2000) quando mencionam da necessidade do relacionamento do gestor com funcionários e clientes e do papel importante do gerente na formulação e na execução da estratégia no varejo, além da atuação empreendedora (proativa) para melhorar sua unidade de trabalho.

\section{REFERÊNCIAS BIBLIOGRÁFICAS}

ALBERTIN, A. L. Comércio Eletrônico: Modelo, Aspectos e Contribuições de sua Aplicação. São Paulo: Atlas, 2001.

COBRA, M.; RANGEL, A. Serviços ao cliente: uma estratégia competitiva. São Paulo: Atlas, 1992. . Administração de Marketing no Brasil. $3^{\text {a }}$ ed. Rio de Janeiro: Elsevier, 2009 . Marketing básico: uma abordagem brasileira. São Paulo, Atlas, 1997.

CASTRO, L. T.; NEVES, M. F. Administração de vendas: planejamento, estratégia e gestão. 1. ed. São Paulo: Atlas, 2005.
DOIN, E.; SILLAS, E. P. Marketing no varejo. Curitiba: Ibpex, 2007.

DRUCKER, P. O melhor de Peter Drucker - A administração. São Paulo: Nobel, 2001.

DUNNE P.; LUSCH R. F. Retailing. Dryden Press, 1999.

E-BIT - Comparativo do consumidor virtual e do varejo. Disponível em: https://www.empresa.ebit.com.br. Acesso em: 10 mai.2016.

E-COMMERCE. Disponível em : http://www.e-commerce.org.br. Acesso em: 15 agos. 2015.

ETZEL, M. J.; WALKER, B. J.; STANTON, W. J. Marketing. São Paulo: Makron Books Ltda, 2001

GODOY, A. S. Introdução à pesquisa qualitativa e suas possibilidades. In Revista de Administração de Empresas, v. 35 n.2 Mar/Abril, 1995.

GIL, A. C. Como elaborar projetos de pesquisa. 4. ed. São Paulo, Atlas, 2002.

GRÖNROOS, C. Marketing: gerenciamento e serviços - a competição por serviços na hora da verdade. Rio de Janeiro: Campus, 1995.

KOTLER, P. Administração de Marketing, Atlas, 1998

. Administração de marketing.

$12^{\mathrm{a}}$ ed. São Paulo: Prentice Hall, 2000

KOTLER, P.; ARMSTRONG, G.; Princípios de marketing. 9. Ed. São Paulo: Prentice Hall, 2003.

KOTLER, P.; KARTAJAYA, H.; SETIAWAN, I. Marketing 3.0: as forças que estão definindo o novo marketing centrado no ser humano. Rio de janeiro: Elsevier, 2010. 
LACERDA, Flávia Alves de Brito. Gestão da qualidade: fundamentos daexcelência. Brasília: SEBRAE, 2005.

LAS CASAS, A. L. A Profissão de Vendas; In: Técnicas de Vendas. São Paulo:Atlas, 1994.

Administração de vendas. 7. ed.

São Paulo: Atlas, 2004.

LEVY, M.; WEITZ, B. A. Administração de Varejo. Tradução Erika Suzuki. São Paulo:

Atlas, 2000.

LUCENA, F.; MORGADO, M. Gerente do varejo, uma discussão que vale a pena. In Marketing de varejo. 4 ed. São Paulo: Atlas, 2006.

MACEDO, G. B. de. Empregue seu Talento.

São Paulo: Cultura Associados, 2001.

MALHOTRA, N. K. Pesquisa de Marketing: Uma Orientação Aplicada.

Porto Alegre: Bookman, 2001.

McCARTHY, E. J. Marketing básico: uma visão gerencial. Rio de Janeiro: Zahar, 1976.

MINTZBERG, $\mathrm{H}$. The nature of managerial work. New York: Harpe Collins Publishers, 1973.

MINTZBERG, H. Managing: desvendando o dia a dia da gestão. Porto Alegre:

Bookman, 2010.

MORGADO, M. G.; GONÇALVES, M. N. Varejo: administração de empresas comerciais. $3^{\text {a }}$ edição. São Paulo: Editora Senac, 2001.

MORGADO, M. G. Comportamento do Consumidor On-line: Perfil , uso da
Internet e atitudes. Dissertação. Programa de Pós-Graduação em Administração, Fundação Getúlio Vargas, Escola de Administração de Empresas de São Paulo. São Paulo, 2003.

NAKAGAWA, S. D. Y. A Lealdade de Consumidores nos Ambientes de Comércio On-line e Off-line. Tese Apresentada ao Departamento de Administração da Faculdade de Economia, Administração e Contabilidade da Universidade de São Paulo. São Paulo, 2008 .

NEVES, A. R. Qualidade no atendimento: a chave para o seu sucesso pessoal e empresarial. Rio de Janeiro: Quality mark, 2006.

PARASURAMAN, A.; ZEITHAML, V.; MALHOTRA, A. A multiple-item scale for assessing electronic service quality. Journal of Service Research, v.7, n.3, 2005.

PARENTE, J. Varejo no Brasil: gestão e estratégia. São Paulo: Atlas, 2000

RICHARDSIN, R. J et al. Pesquisa social: métodos e técnicas. São Paulo: Atlas, 1999.

STANTON, W. J.; SPIRO, R. Administração de Vendas.Tradução Dalton Conde de Alencar. 10. ed. Rio de Janeiro: LTC - Livros Técnicos e Científicos Editora S.A., 2000.

VERGARA, S. C. Projetos e relatórios de pesquisa em administração. 5. ed. São Paulo: Atlas, 2004.

ZAMBERLAN, L. et al. Pesquisa em ciências sociais aplicadas. Ijuí: Ed. Unijuí, 2014. 